\title{
Evaluating the interchangeability of infrared and digital devices with the traditional mercury thermometer in hospitalized pediatric patients: an observational study.
}

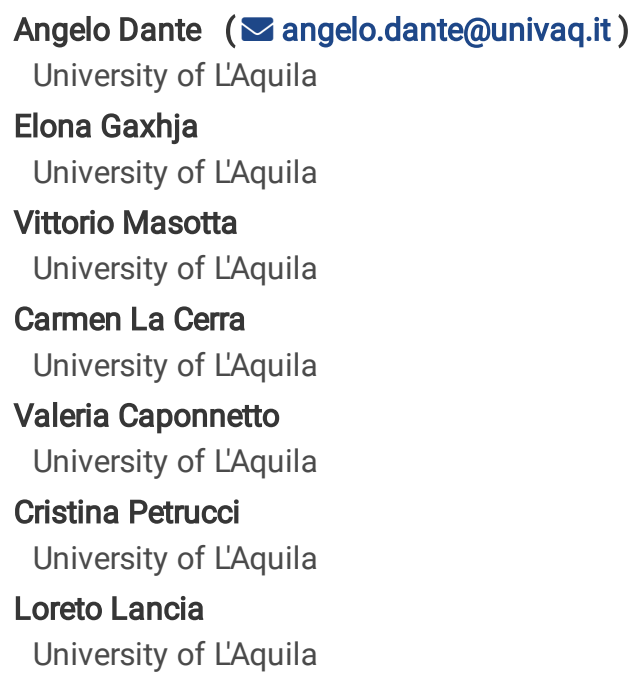

\section{Research Article}

Keywords: Body temperature, children, Bland-Altman analysis, thermometers, mercury thermometers,

Posted Date: September 16th, 2020

DOI: https://doi.org/10.21203/rs.3.rs-78040/v1

License: (c) (i) This work is licensed under a Creative Commons Attribution 4.0 International License. Read Full License 


\section{Abstract}

A gradual replacement of the mercury thermometers with alternative devices is ongoing around the world as effect of the global strategies to reduce mercury pollution. However, to reduce the risks of misdiagnosis, unnecessary treatments, and omission of care in the pediatric population, more evidence on the reliability and validity of alternative thermometers are needed. The aim of this comparative observational study was to detect any differences in temperature measurements between the gold-standard axillary mercury thermometer (AXL $\left.L_{M E R}\right)$ and the alternative devices. Temperature values in Celsius $\left({ }^{\circ} \mathrm{C}\right)$ were simultaneously measured in a group of Albanian children aged up to 14 years using both $\left(A X L_{M E R}\right)$ and digital axillary thermometers $\left(A X L_{D G T}\right)$, as well as forehead and tympanic infra-red thermometers. The $A X L_{D G T}$ device, compared with the $A X L_{M E R}$, showed no clinically significant difference in the mean values $\left(-0.04 \pm 0.29^{\circ} \mathrm{C}\right)$ and the narrowest $95 \%$ Level of Agreement $\left(+0.53{ }^{\circ} \mathrm{C}\right.$ to $\left.-0.62{ }^{\circ} \mathrm{C}\right)$ in the paired comparisons. For cut-off points of $37.0^{\circ} \mathrm{C}$ and $37.5^{\circ} \mathrm{C}$, the $A X L_{D G T}$ showed the highest levels of sensitivity (67.4\% and $72.5 \%)$ and specificity ( $95.3 \%$ and $99.1 \%$ ) in detecting fever. This study indicates that the $\mathrm{AXL}_{\mathrm{DGT}}$ thermometer may prove the better option since it adequately balances accuracy, safety and children's comfort.

\section{Introduction}

Body temperature (BT) measurement is an essential component of pediatric health assessment in hospital settings and elsewhere. Normal BT values range from $36.5^{\circ} \mathrm{C}$ to $37.5^{\circ} \mathrm{C}$ depending on physiological variations, patient characteristics, and sites of measurement ${ }^{1,2}$.

Since BT values, when associated to the clinical assessment, contribute to orient diagnoses and therapies for children, unreliable measurements may lead to misdiagnosis, omittance or delay of necessary treatments and prescription of unnecessary therapies or exams $^{3-5}$. For these reasons, BT measurement should be carried out with valid and reliable devices ${ }^{6}$.

In this regard, intra-corporeal thermometry methods used to obtain 'core' temperature, such as thermistor probes inserted in the pulmonary artery or oesophagus, are considered the gold-standard for BT measurement ${ }^{7}$. However, these methods are invasive and expensive, could expose patients to the risk of complications, and are generally used in critically ill patients ${ }^{8,9}$.

Historically, the mercury thermometers were accepted as the 'clinical gold-standard devices' for BT measurement in daily clinical practice and, among them, those axillary $\left(A X L_{M E R}\right)$ have been used routinely everywhere around the world ${ }^{7,10,11}$.

Some evidence demonstrates the $A X L_{M E R}$ thermometer measurements only to be 'proxy' of core $B T$ values since they underestimate the internal $B T$ of about $1.0^{\circ} \mathrm{C}$. However, the lack of accurate alternative devices, comfort for patients, and easiness of use made $A X L_{M E R}$ thermometersessential for clinical practice ${ }^{2,12}$.

However, the risk for environment and public health due to mercury pollution derived from anthropic activities made mercury a global concern and led Governments to adopt strategies aimed to reduce its emissions in the atmosphere, soil, and water ${ }^{13}$. In this regard, a series of initiatives aimed at banning the production, import, and export of mercury products, as well as controlling manufacturing processes in which this substance is used, have been carried out ${ }^{13-15}$. In accordance with these initiatives, a gradual replacement of mercury thermometers with alternative devices is ongoing in the health systems of countries who are signatories to the Minamata Convention ${ }^{13}$.

Among the alternative devices, galinstan-in-glass, digital, and infrared thermometers are currently available in the market; they are easy to use, cost-effective, non-invasive, and safe ${ }^{16-18}$. Nevertheless, only digital axillary ( $\left.A X L_{D G T}\right)$ and infrared tympanic $\left(T Y M_{I R}\right)$ thermometers are currently recommended in pediatric clinical practice ${ }^{1,5,1920}$, since the lack of data confirming the accuracy of other devices to diagnose fever does not allow them to be considered useful tools for BT measurement in pediatric patients ${ }^{8,9}$. However, the guidelines and recommendations on BT measurement of pediatric patients are based on moderate quality evidence, and most of the available studies aimed to explore the validity and reliability of the alternative devices as 'proxy' measures of core BT, instead of exploring their interchangeability with the historical gold standard $\left(A X L_{M E R}\right){ }^{10,19,21,22}$.

Therefore, in order to increase the available evidence and, thereby, reduce the risks of misdiagnosis, unnecessary treatments, and omission of care in the pediatric population, research on the reliability, validity, and interchangeability of the alternative devices in clinical practice is ongoing globally ${ }^{6,10,18,23-26}$. It is in this regard that we undertook this study, which aimed to detect any differences in BT measurements between the old clinical gold standard $A X L_{M E R}$ thermometer and those new digital and infrared in a pediatric setting. The study hypothesis was that no clinically significant differences existed between the old mercury thermometer and the new devices, especially in regard to sensitivity and specificity for fever detection. 


\section{Methods \\ Study design, setting, and participants}

A comparative observational study was conducted from September 2018 to January 2019 in a fifty-bed pediatric ward of a general hospital in Albania, where about one thousand patients are admitted annually for a broad spectrum of medical health issues ranging from respiratory diseases to infectious diseases such as enteritis. Albania is one of the developing countries of Europe where the use of mercury thermometers was still allowed when the study was conducted.

Using consecutive sampling, all pediatric patients aged up to 14 years and requiring BT measurements were enrolled if the parents gave their informed consent. Hospitalized children in critical conditions or those unable to tolerate multiple BT measurements were excluded. Referring to subjects that had to receive BT measurements twice a day, a sample size of at least 327 children was estimated to provide a 95\% power (1- $\beta$ ) and a 5\% a error in detecting BT measurement differences, using G* Power 3.1.9.2 software.

\section{Variables}

In order to perform a secondary analysis of subgroups potentially affecting differences in BT detection between the compared thermometers, data on demographic and clinical variables, such as age, gender, site of BT measurements, admission diagnosis, and antipyretic drugs administration were also collected. In this study, $A X L_{M E R}$ was considered the gold standard while $A X L_{D G T}$, $F H D_{I R}$, and TYM $M_{\mathbb{R}}$ were the alternative methods.

\section{Instruments and data collection}

Following each thermometer manufacturer's instructions, BT measurements were collected, twice a day, at 8:00 in the morning and at 5:00 in the afternoon, from axillary, tympanic, and forehead sites simultaneously.

For axillary temperature detection, GEA Medical Mercury thermometers (Product code 10901902464, GEA ${ }^{\circledR}$, Indonesia) and Easy Touch Digital thermometers (Product code 00006929000000 , Chicco ${ }^{\circledR}$, Italy) were used, whereas for tympanic and forehead temperature detection Infra-Red Comfort Quick devices (Product code 00000656000000 , Chicco ${ }^{\circledR}$, Italy) and Infra-Red Easy Touch thermometers (Product code $00004757100000, \mathrm{Chicco}^{\circledR}$, Italy) were respectively used. The manufacturer of the alternative thermometers reported a $\pm 0.1^{\circ} \mathrm{C}$ measurement error for the $A X L_{D G T}$ device (BT range from $35.5^{\circ} \mathrm{C}$ to $42.0^{\circ} \mathrm{C}$ ) and a $\pm 0.2^{\circ} \mathrm{C}$ for both $T_{Y M} M_{I R}$ and $F H D_{I R}$ thermometers $(B T$ range from $35.0^{\circ} \mathrm{C}$ to $42.0^{\circ} \mathrm{C}$ ).

Both the $A X L_{D G T}$ and $A X L_{M E R}$ devices were placed deeply in each child's left or right armpit with the arm being held steady taking one and five minutes to measure $B T$, respectively. The $A X L_{M E R}$ was used after making the mercury level down to the minimum (35.0 $\left.{ }^{\circ} \mathrm{C}\right)$. Recordings were timed through a chronometer for the $A X L_{M E R}$ and the beeper of the $A X L_{D G T}$.

The tympanic BT was detected by scanning the infrared radiation from the tympanic membrane for one second. For each measurement, the probe of the TYM $M_{\mathbb{R}}$ thermometer was replaced and the measurements in the ear in contact with pillows were avoided.

As recommended by the manufacturer, the forehead temperature was measured by scanning the infrared radiation from the temporal artery for about five-eight seconds (maximum 30 seconds). Using the same side for temporal measurements allowed to prevent BT differences due to blood vessels depth.

All measurements were performed on clean and dry skin, waiting at least 30 minutes after meals or baths. Prior to their use, all thermometers were calibrated according to the manufacturer's instructions.

To ensure the accuracy of measurements, five nurses, after having attended a theoretical-practical training about the characteristics and usage of new thermometers and about the research protocol, performed all BT measurements and recorded the data on a BT flowsheet under the supervision of one of the researchers.

\section{Data analysis}


Data were summarized using frequencies (n), percentages (\%), central tendency indexes (mean, median), and dispersion measures standard deviation (SD), interquartile range (IQR), range.

Differences between measurement results of the mercury thermometers and the alternatives devices were statistically checked using paired sample $t$-tests and visually compared using the Bland-Altman scatterplots 27. Pearson's $r$ coefficient was calculated to explore the correlation between the investigated devices. Considering as not desirable the differences between the gold standard's and other measurements, a maximum significant level of 0.05 was considered for the $t$-tests, whereas for the Bland-Altman analysis $95 \%$ Limits of Agreement (LoA), defining the range within which most BT differences fell, were computed with the formula 'mean of BT measurement differences $\pm 1.96 * \mathrm{SD}^{\prime 27,28}$; mean values of $\pm 0.5^{\circ} \mathrm{C}$ were considered the maximum acceptable LoA based on the available evidence 8 .

Finally, to analyze the diagnostic accuracy of the alternative devices in detecting fever, their sensitivity 'true positives' / ('true positives' + 'false negatives') and specificity 'true negatives' / ('true negatives' + 'false positives') were calculated ${ }^{29}$. For this purpose it needed to fix cutoff to discriminate the fever/no-fever conditions and since normal BT values are related to the site of measurement and no international agreement has been reached on the exact values to define fever ${ }^{12,30,31}$, this study considered the peripheral $\mathrm{BT} \geq 37.0^{\circ} \mathrm{C}$ and $\geq 37.5^{\circ} \mathrm{C}$ as cut-off values to include febrile patients.

All data were analyzed using IBM SPSS version 25.0 (IBM Corp., Armonk, New York, USA).

\section{Ethics}

This study is a result of an international cooperation between Italian and Albanian academy institutions and was conducted in accordance with the Declaration of Helsinki. The study was approved by the Institutional Review Board of the Albanian hospital where the research was conducted (letter of approval \#1693/2018). Before data collection, a written informed consent was obtained from the children's parents. Nevertheless, no child was forced to participate if there was verbal or non-verbal refusal.

\section{Results}

\section{Participants}

A total of 356 pediatric patients were enrolled (Table 1). Two hundred and eleven (59.3\%) were male and the average age was $3.0 \pm 3.0$ years (median 2.0; IQR 3.1; range 0-14). The main reasons for hospitalization were respiratory (209, 59.3\%) and gastrointestinal diseases $(73,20.6 \%)$. Forty patients $(11.2 \%)$ received antipyretic drug administration before BT measurements.

\section{Differences in BT measurements between the alternative devices and gold standard}

As shown in Figure 1, in a paired comparison with the $A X L_{M E R}$ device, both $A X L_{D G T}$ and $T Y M_{I R}$ showed slightly lower mean $B T$ values, ranging from $-0.04{ }^{\circ} \mathrm{C}$ to $-0.12{ }^{\circ} \mathrm{C}$, respectively $(\mathrm{p}<0.001)$, while mean differences between $A X L_{M E R}$ and $F H D_{I R}\left(0.03{ }^{\circ} \mathrm{C}\right)$ were not statistically significant $(p=0.141)$. A strong correlation was detected between BT measurements performed with $A X L_{D G T}$ and $A X L_{M E R}$ thermometers $(r=$ 0.844), while moderate correlations were detected between $\operatorname{TYM}_{\mathbb{I R}}$ and $\mathrm{AXL}_{\mathrm{MER}}(r=0.623)$ and $\mathrm{FHD}_{\mathrm{IR}}$ and $\mathrm{AXL}_{\mathrm{MER}}(r=0.665)$.

Table 1. Participants' characteristics $(n=356)$ 


\begin{tabular}{|c|c|c|c|}
\hline & & $\mathbf{n}$ & $\%$ \\
\hline \multicolumn{4}{|c|}{ Gender } \\
\hline & Male & 211 & 59.3 \\
\hline & Female & 145 & 40.7 \\
\hline Age & $($ Mean \pm SD) & \multicolumn{2}{|c|}{$(3.0 \pm 3.0)$} \\
\hline \multicolumn{4}{|c|}{ Admission diagnosis (grouped by system)* } \\
\hline & Respiratory & 209 & 59.0 \\
\hline & Gastrointestinal & 73 & 20.6 \\
\hline & Neurologic and sensorial & 29 & 8.2 \\
\hline & Urinary & 9 & 2.5 \\
\hline & Locomotor and articular & 3 & 0.8 \\
\hline & Other & 31 & 8.8 \\
\hline \multicolumn{4}{|c|}{ Antipyretic drugs administered before BT measurements } \\
\hline & Yes & 40 & 11.2 \\
\hline & No & 316 & 88.8 \\
\hline
\end{tabular}

\section{*Missing data $\mathrm{n}=3$}

With reference to daily BT variations, the average data of the measurements taken in the morning and afternoon show that all the alternative thermometers reported values less than that reported by the mercury thermometer (Figure 2), although all the BT variations fell within the maximum measurement error provided by the manufacturer for each device.

The Bland-Altman scatterplots (Figure 3a, 3b, and 3c) show the narrowest $95 \%$ LoA $\left(+0.53^{\circ} \mathrm{C}\right.$ to $\left.-0.62{ }^{\circ} \mathrm{C}\right)$ for the measurement comparison between $A X L_{M E R}$ and $A X L_{D G T}$, and the broadest $95 \%$ LoA $\left(+0.81{ }^{\circ} \mathrm{C}\right.$ to $\left.-1.04{ }^{\circ} \mathrm{C}\right)$ for the comparison between $A X L_{M E R}$ and $T_{Y M} M_{\mathbb{R}}$ values. In all the Bland-Altman scatterplots, the magnitude of differences between the alternative and gold-standard thermometers decreased when the average BT values increased.

Taking $\pm 0.5^{\circ} \mathrm{C}$ as the maximum clinically acceptable difference, when the three alternative devices were compared to the gold standard, 94.0\% of $A X L_{D G T}$ values fell within these cut-offs, followed by $\mathrm{FHD}_{\mathbb{I R}}(83.4 \%)$, and then $\operatorname{TYM}_{\mathbb{R}}$ (79.3\%) (Figure 3d).

In addition, across the entire sample, $A X L_{D G T}$ thermometer showed the highest levels of sensitivity and specificity in detecting fever, regardless of the established cut-offs (Table 2).

Table 2. Diagnostic accuracy of alternative devices to detect fever compared to Gold Standard (Measurements $=711$ )

\begin{tabular}{|llll|}
\hline Indexes & $\mathbf{A X L}_{\mathrm{DGT}}$ & $\mathbf{F H D}_{\mathbf{I R}}$ & TYM $_{\mathbf{I R}}$ \\
\hline $\left.\mathbf{( B T} \geq \mathbf{3 7 . 0}{ }^{\circ} \mathbf{C}\right)$ & & & \\
\hline Sensitivity & 67.4 & 50.4 & 47.4 \\
\hline Specificity & 95.3 & 91.7 & 94.8 \\
\hline (BT $\left.\geq \mathbf{3 7 . 5}{ }^{\circ} \mathbf{C}\right)$ & & & \\
\hline Sensitivity & 72.5 & 64.7 & 51.0 \\
\hline Specificity & 99.1 & 96.8 & 98.3 \\
\hline
\end{tabular}




\section{Discussion}

This study aimed at detecting any differences in BT measurements between the old gold-standard $A X L_{M E R}$ thermometer and the new digital and infrared thermometers in a hospital pediatric setting in Albania where mercury thermometers were still allowed despite the Minamata Convention due to a transition phase related to the in-country resources and capacities ${ }^{13}$. This study could not be currently conducted since on 26 May 2020, the Government of Albania deposited its instrument of ratification, becoming the 120th Party to the Minamata Convention. For this reason, the window of opportunity exploited in this study has been closed and the mercury thermometer cannot longer be used in Albania resulting in beneficial effects for the environment, children, and community.

Following the ban on mercury, in the last 10 years numerous environment-friendly devices have been introduced into clinical settings in many countries around the world to replace mercury thermometers, and a great amount of research has been conducted to explore their

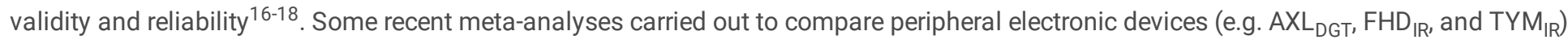
with central devices (e.g. bladder, esophageal, and rectal) indicated that the peripheral devices showed poor accuracy when used to estimate core BT and inadequate sensitivity when used for fever detection in adults and children ${ }^{8,9,22}$. However, using a different research methodology, other authors, comparing the peripheral electronic devices, achieved contradictory evidence ${ }^{32-35}$. For example, some studies found that $F H D_{\mathbb{R}}$ thermometers could serve as a good alternative to $A X L_{D G T}$ due to their user-friendliness and speed of use ${ }^{36}$, while others, reporting great mean differences between the investigated devices, did not consider the $F H D_{\mathbb{R}}$ device as accurate as the $A X L_{D G T}$ thermometer $24,34,35$.

The research approaches in the above-mentioned studies had two distinct goals: comparing peripheral devices with central ones and exploring the level of agreement among the alternative thermometers. Surprisingly, available evidence has not completely dissolved concerns about the validity and reliability of the new thermometers and have not fully allayed nurses' doubts emerging from clinical contexts. In fact, when nurses need to make their clinical decisions on the basis of BT values detected with the alternative peripheral devices, they need to know if these new thermometers (e.g. $A X L_{D G T}, F H D_{\mathbb{R}}$, and $T Y M_{\mathbb{R}}$ ) are as reliable at least as the old mercury device they used for a long time. To tackle this issue and contribute to the global debate, we conducted this perspective pragmatic research.

In the light of our results, the research hypothesis of no clinically significant differences between the old gold-standard mercury thermometer and the new devices should be partially rejected.

In fact, although moderate to strong significant direct correlations were found between BT values detected by all the alternative devices and those by the $\mathrm{AXL}_{\mathrm{MER}}$ ( $r=$ from 0.623 for $T Y M_{\mathbb{R}}$ to 0.844 for $A X L_{D G T}$ ), also significant mean differences were found for the paired $B T$ comparisons between each of $A X L_{D G T}$ and $T Y M_{I R}$ and the mercury thermometer $\left(-0.04{ }^{\circ} \mathrm{C}\right.$ and $-0.12{ }^{\circ} \mathrm{C}$, respectively). However, in this case statistically significant differences cannot correspond to a strong clinical significance since it is unlikely that a maximum difference of $-0.12{ }^{\circ} \mathrm{C}$ can affect some clinical judgements, such as drugs administration or caring interventions. Nevertheless, considering the poor clinical significance of these differences, it would be hazardous to state that the new alternative devices are all equally reliable tools for BT measurement in children.

In fact, beyond the statistical significance, in the visual analysis of difference between measurements (Bland-Altman scatterplots) it is noticeable that the $A X L_{D G T}$ values are the closest to the gold standard's since $95 \%$ of their differences fell within the narrowest range ( $95 \%$ LoA $=-0.62{ }^{\circ} \mathrm{C}$ to $+0.53^{\circ} \mathrm{C}$ ). In addition, the $A X L_{D G T}$ showed the highest percentage $(94.0 \%)$ of $B T$ differences within the clinical acceptable value of $0.5^{\circ} \mathrm{C}^{8}$. For these reasons, $\mathrm{AXL}_{\mathrm{DGT}}$ thermometer should be considered most similar to the old gold-standard mercury thermometer and, in accordance with current guidelines, may be preferable for measuring BT in children ${ }^{3-5,20}$.

$\mathrm{FHD}_{\mathbb{R}}$ and $\mathrm{TYM}_{\mathrm{IR}}$ devices showed poor agreement with $\mathrm{AXL} \mathrm{L}_{\mathrm{MER}}$ thermometer, exhibiting broader $95 \%$ LoAs $\left(-0.92{ }^{\circ} \mathrm{C}\right.$ to $0.87^{\circ} \mathrm{C}$ and $-1.04{ }^{\circ} \mathrm{C}$ to $0.81{ }^{\circ} \mathrm{C}$, respectively) and more differences higher than $0.5^{\circ} \mathrm{C}$ compared to $A X L_{D G T}$ thermometer. In the light of this findings, it would not be cautious to indicate $F H D_{\mathbb{R}}$ and $T Y M_{\mathbb{R}}$ as the first choices for $B T$ measurements in children. However, in pediatric clinical settings where $\mathrm{FHD}_{\mathbb{R}}$ and TYM $\mathrm{M}_{\mathbb{R}}$ are used ${ }^{32,36}$, we suggest that $\mathrm{BT}$ values be validated through clinical observation and $A X L_{D G T}$ thermometer be used in case of discrepancy.

Furthermore, $A X L_{D G T}$ thermometer also showed better performance in screening for fever than $F H D_{\mathbb{R}}$ and $T Y M_{\mathbb{R}}$ devices, even if in this study, as in some other studies, all the investigated devices showed moderate to low sensitivity and high specificity in detecting fever ${ }^{8,9,22}$. In fact, even if to a lesser extent than the other alternative devices, also the $A X L_{D G T}$ thermometer resulted in a higher proportion of falsenegative than false-positive readings, and this could be explained by the tendency to underestimate the gold-standard measurements 
adopted in this study. In practice, also using the $A X L_{D G T}$ thermometer, in a minimal proportion of children found to be non-febrile, fever could not be ruled out with certainty. In this regard, it is always advisable, in accordance with current guidelines, a conservative approach to protect children from missed care, by repeating BT measurements or using rectal thermometers to confirm fever, especially when clinical signs and symptoms contrast with detected BT values ${ }^{5,20}$.

\section{Practice implication}

The results of this study suggest that $A X L_{D G T}$ thermometer may be the best choice for $B T$ measurement in pediatric settings, considering especially that this device adequately balances accuracy, safety, and children's comfort. Even if there are practical reasons suggesting the use of $T Y M_{I R}$ and $F_{I_{R}}$ thermometers in pediatric clinical practice, such as their ease of use, speed of measurements and improved hygiene, the results of this study show that these devices cannot be considered interchangeable with the gold standard adopted in this study, and $A X L_{D G T}$ should be preferred, especially if there are clinical doubts. However, considering the performance of $A X L_{D G T}$ in the screening of fever, clinical decisions should not be based exclusively on BT values, but, in accordance with current guidelines, it is always advisable assessing children for the presence or absence of signs and symptoms potentially associable with fever ${ }^{5}$. Assessing the skin colour and turgor, respiratory function, cardio-circulatory condition, the child's activity, and the presence of headache, shiver, and nausea provide excellent criteria to confirm or doubt a BT value ${ }^{5,20}$. This last recommendation should be strongly considered for clinical practice especially during epidemic events, such as the current Coronavirus disease 2019 (COVID-19) pandemic. In this regard, one of the special accommodations made in clinical practice and other contexts is the use of the infrared thermometers. For its 'no contact' process aimed at limiting the virus spread, the $\mathrm{FHD}_{\mathrm{IR}}$ device has become the most widely accepted thermometer in this pandemic. However, considering that in this study fever $\left(\geq 37.5^{\circ} \mathrm{C}\right)$, in about one-third of febrile children could not be detected with the FHD $\mathrm{IR}_{\mathrm{R}}$ device, temperature screening alone should be avoided in every context since it may not be very effective, as also supported by previous evidence ${ }^{9}$. Those signs and symptoms commonly present in children with Coronavirus disease 2019 , such as fatigue, dry cough, and other respiratory symptoms, should be considered along with BT values ${ }^{37,38}$.

\section{Limitations of the study}

The strengths of this study included the adequate sample size of pediatric patients, the measurement of BT in a real clinical setting, the use of axillary mercury thermometers as the gold standard, and the use of appropriate statistical methods for data analysis. However, the results of this study should be accepted bearing in mind the monocentric approach of the study and the differences between core and peripheral BTs.

In conclusion, the results of this study confirmed the $A X L_{D G T}$ device as the best alternative to the $A X L_{M E R}$ thermometer in detecting children's BT both in cases of fever or not.-

However, according to current guidelines, when clinical signs and symptoms contrast with detected BT values, it is recommended repeating BT measurements or using rectal thermometers.

\section{Declarations}

\section{Acknowledgements}

We thank children and their parents for participation. We also thank Dr. Brikena Gjata, Dr. Esmeralda Qevani, Dr. Klementina Xhaferri, and Dr. Erinda Vreto for their assistance in data collection process and Nurses Head Dr. Hedije Bylyku and Dr. Emanuela Ferra for their assistance with patient enrolment.

\section{Authors' contributions}

DA: participated in the conception and design of the work, performed the data analysis and drafted the manuscript GE: participated in the conception of the work, participated in the acquisition of data and drafted the manuscript. MV, CV, CC: participated in the conception of the work and drafted the manuscript PC: participated in the conception and design of the work, and critically revised the manuscript. LL: participated in the conception and design of the work, performed the data analysis, and critically revised the manuscript. All authors read and approved the final manuscript

\section{Competing interests}

The authors declare that they have no competing interests. 


\section{Data availability}

Data and materials are available from the corresponding author on reasonable request.

\section{Ethics declarations}

This study is a result of an international cooperation between Italian and Albanian academy institutions and was conducted in accordance with the Declaration of Helsinki. The study was approved by the Institutional Review Board of the Albanian hospital where the research was conducted (letter of approval \#1693/2018). Before data collection, a written informed consent was obtained from the children's parents. Neverthless, no child was forced to participate if there was verbal or non-verbal refusal from the child.

\section{Funding}

The authors disclosed receipt of the following institutional financial support: RIA Funds (Research and Innovation Action) - Department of Life, Health, and Environmental Sciences - University of L'Aquila - 2018.

Department of Life, Health, and Environmental Sciences had no part in the design of the study, collection, analysis, and interpretation of data and in writing the manuscript.

\section{References}

1. World Health Organization. Pocket book of hospital care for children: guidelines for the management of common illnesses with limited resources. https://www.who.int/maternal_child_adolescent/documents/9241546700/en/ (2005).

2. Pontieri, G.M. Patologia generale \& Fisiopatologia Generale 3rd ed. (Piccin, 2012).

3. Chiappini, E. et al. 2016 Update of the Italian Pediatric Society Guidelines for Management of Fever in Children. J Pediatr. 180, 177183e1 (2017).

4. Green, R. et al. Management of acute fever in children: guideline for community healthcare providers and pharmacists. SAfr Med J. 103, 948-954 (2013).

5. National Institute for Health and Care Excellence. Fever in under 5s: assessment and initial management. In: Clinical Guideline NG143. https://www.nice.org.uk/guidance/ng143 (2019).

6. Opersteny, E. et al. Precision, Sensitivity and Patient Preference of Non-Invasive Thermometers in a Pediatric Surgical Acute Care Setting. J Pediatr Nurs. 35, 36-41 (2017).

7. Chatproedprai, S., Heamawatanachai, K., Tempark, T. \& Wananukul, S. A Comparative Study of 3 Different Methods of Temperature Measurement in Children. J Med Assoc Thai. 99, 142-149 (2016).

8. Geijer, H., Udumyan, R., Lohse, G. \& Nilsagard, Y. Temperature measurements with a temporal scanner: systematic review and metaanalysis. BMJ Open. 6, e009509 (2016).

9. Kiekkas, P., Aretha, D., Almpani, E. \& Stefanopoulos, N. Temporal Artery Thermometry in Pediatric Patients: Systematic Review and Meta-Analysis. J Pediatr Nurs. 46, 89-99 (2019).

10. Periasami, V. Diagnostic accuracy of digital thermometer compared to mercury in glass thermometer for measuring temperature in children. Int J Contemp Pediatr. 4, 1476-1479 (2017).

11. Wang, G., Wang, W., Li, K. \& Liu, H. A digital thermometer with fast response and high precision. In: 7th International Conference on Biomedical Engineering and Informatics, Dalian, 504-10 (2014).

12. Sund-Levander, M., Forsberg, C. \& Wahren, L.K. Normal oral, rectal, tympanic and axillary body temperature in adult men and women: a systematic literature review. Scand J Caring Sci. 16, 122-128 (2002).

13. United Nations Environment Programme. Guidance Document Developing a National Action Plan to Reduce and, Where Feasible, Eliminate Mercury Use in Artisanal and Small-Scale Gold Mining. http://www.briloon.org/uploads/BRI_Documents/Tropical_Program/ASGM/National\%20Action\%20Plan_draft\%20guidance\%20v12.pdf (2017).

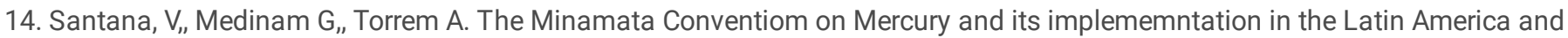
Carribean region. http://mercuryconvention.org/Portals/11/documents/publications/report_Minamata_LAC_EN_FINAL.pdf (2014).

15. United Nations Environment Programme. Minamata Convention on Mercury Text and Annexes. http://www.mercuryconvention.org/Portals/11/documents/Booklets/COP1\%20version/Minamata-Convention-booklet-eng-full.pdf (2017). 
16. El-Radhi, A.S. Determining fever in children: the search for an ideal thermometer. Br J Nurs. 23, 91-94 (2014).

17. Schreiber, S. et al. Galinstan thermometer is more accurate than digital for the measurement of body temperature in children. Pediatr Emerg Care. 29, 197-199 (2013).

18. Sollai, S. et al. Performance of a non-contact infrared thermometer in healthy newborns. BMJ Open. 6, e008695 (2016).

19. Chiappini, E. et al. Update of the 2009 Italian Pediatric Society Guidelines about management of fever in children. Clin Ther. 34, 16481653.e3. (2012).

20. Royal College of Nursing. Standards for Assessing, Measuring and Monitoring Vital Signs in Infants, Children and Young People In.: Royal College of Nursing, 20 Cavendish Square, London, W1G ORN. Royal College of Nursing. https://www.rcn.org.uk/professionaldevelopment/publications/pub-005942 (2017).

21. Dodd, S.R., Lancaster, G.A., Craig, J.V., Smyth, R.L. \& Williamson, P.R. In a systematic review, infrared ear thermometry for fever diagnosis in children finds poor sensitivity. J Clin Epidemiol. 59, 354-357 (2006).

22. Niven, D.J. et al. Accuracy of peripheral thermometers for estimating temperature: a systematic review and meta-analysis. Ann Intern Med. 163, 768-777 (2015).

23. Apa, H. et al. Clinical accuracy of tympanic thermometer and noncontact infrared skin thermometer in pediatric practice: an alternative for axillary digital thermometer. Pediatr Emerg Care. 29, 992-997 (2013).

24. Franconi, I., La Cerra, C., Marucci, A.R., Petrucci, C. \& Lancia L. Digital Axillary and Non-Contact Infrared Thermometers for Children. Clin Nurs Res. 27, 180-190 (2018).

25. Lake, E.T. et al.Missed Nursing Care in Pediatrics. Hosp Pediatr. 7, 378-84 (2017).

26. Money, N.M. et al.2019 Update on Pediatric Medical Overuse: A Systematic Review. JAMA Pediat. (2020).

27. Bland, J.M. \& Altman, D.G. Measuring agreement in method comparison studies. Stat Methods Med Res. 8, 135-160 (1999).

28. Giavarina, D. Understanding Bland Altman analysis. Biochem Med (Zagreb). 25, 141-151 (2015).

29. Stojanovic, M. et al. Understanding sensitivity, specificity and predictive values. Vojnosanit Pregl. 71, 1062-1065 (2014).

30. Crawford, D.C., Hicks, B. \& Thompson, M.J. Which thermometer? Factors influencing best choice for intermittent clinical temperature assessment. J Med Eng Technol. 30, 199-211 (2006).

31. Oguz, F. et al. Axillary and Tympanic Temperature Measurement in Children and Normal Values for Ages. Pediatr Emerg Care. 34, 169173 (2018).

32. Chiappini, E. et al. Performance of non-contact infrared thermometer for detecting febrile children in hospital and ambulatory settings. J Clin Nurs. 20, 1311-1318 (2011).

33. Dante, A., Franconi, I., Marucci, A.R., Alfes, C.M. \& Lancia L. Evaluating the interchangeability of forehead, tympanic, and axillary thermometers in Italian paediatric clinical settings: Results of a multicentre observational study. J Pediatr Nurs. 52, e21-e25 (2020).

34. Robertson-Smith, J., McCaffrey, F.T., Sayers, R., Williams, S. \& Taylor, B.J. A comparison of mid-forehead and axillary temperatures in newborn intensive care. J Perinatol. 35, 120-122 (2015).

35. Sethi, A., Patel, D., Nimbalkar, A., Phatak, A. \& Nimbalkar S. Comparison of forehead infrared thermometry with axillary digital thermometry in neonates. Indian Pediatr. 50, 1153-1154 (2013).

36. Isler, A., Aydin, R., Tutar Guven, S. \& Gunay S. Comparison of temporal artery to mercury and digital temperature measurement in pediatrics. Int Emerg Nurs. 22, 165-168 (2014)

37. Rasmussen, S.A. \& Thompson L.A. Coronavirus Disease 2019 and Children: What Pediatric Health Care Clinicians Need to Know. JAMA Pediat. (2020).

38. Tagarro, A. et al. Screening and Severity of Coronavirus Disease 2019 (COVID-19) in Children in Madrid, Spain. JAMA Pediat. e201346 (2020).

\section{Figures}


TYM $_{\mathrm{R}}$

Mean $( \pm \mathrm{SD})=36.49( \pm 0.55)$

Median $(\mathrm{IQR})=36.40(0.50)$

Min-Max $=35.00-39.70$

\section{FHD $\mathrm{IR}$}

Mean $( \pm \mathrm{SD})=36.58( \pm 0.58)$

Median $(\mathrm{IQR})=36.50(0.60)$

Min-Max $=35.00-40.20$

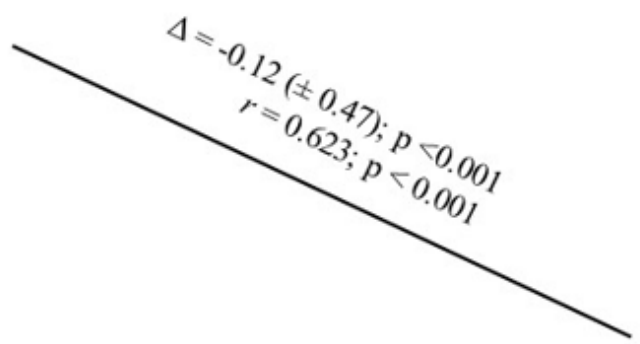

$\Delta=-0.03( \pm 0.46) ; \mathrm{p}=0.141$ $r=0.665 ; \mathrm{p}<0.001$
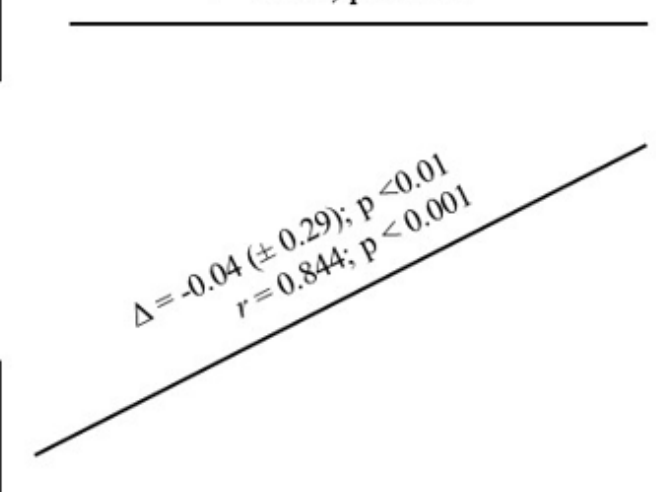

$\mathrm{AXL}_{\mathrm{MER}}$

Mean $( \pm \mathrm{SD})=36.61( \pm 0.53)$

Median $(\mathrm{IQR})=36.50(0.50)$

Min-Max $=35.60-40.00$

\section{Figure 1}

Paired comparisons between the Gold Standard thermometer and the alternative ones (Measurements $=711$ ) 


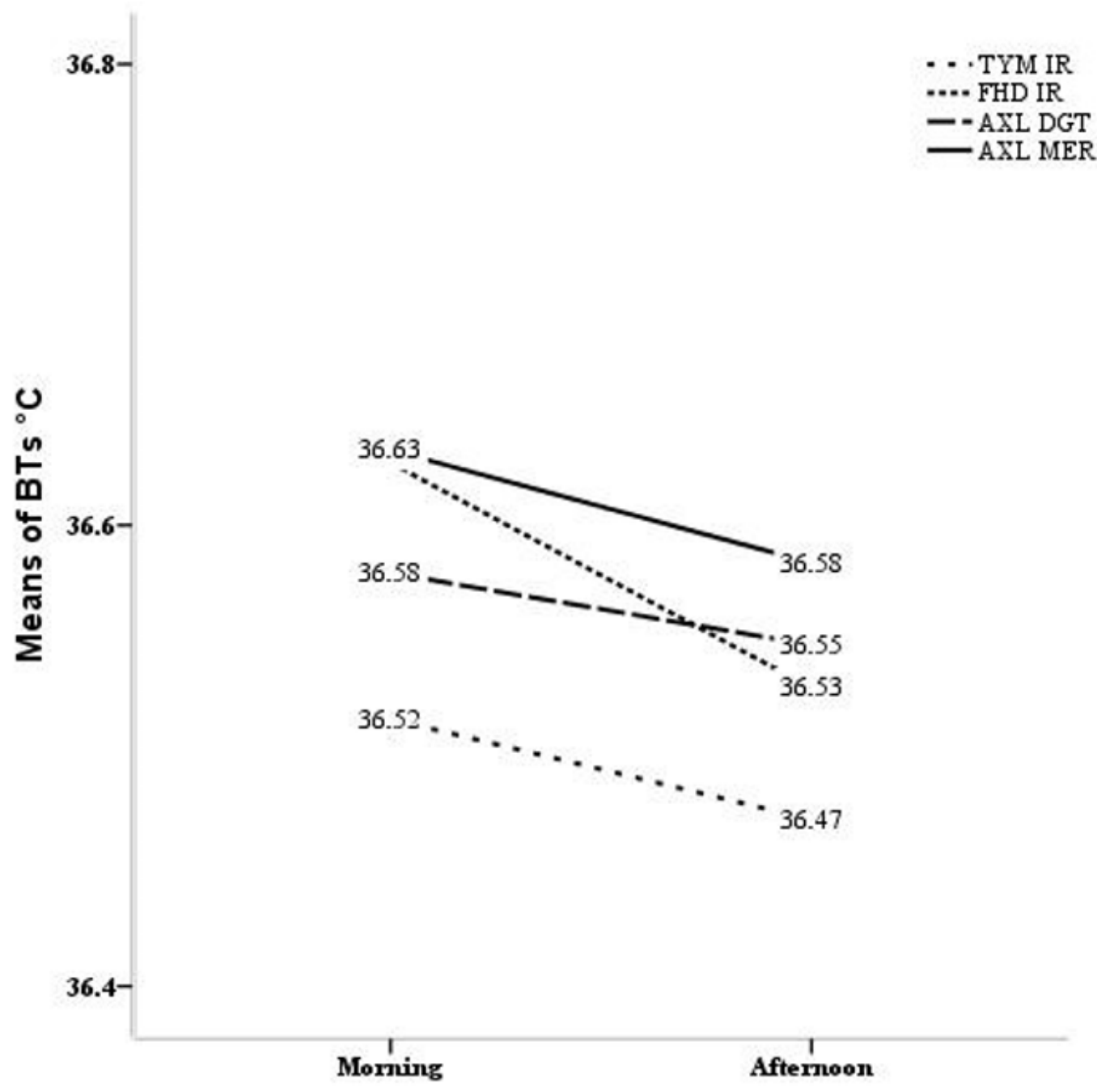

Figure 2

Body temperature values and time of the day 


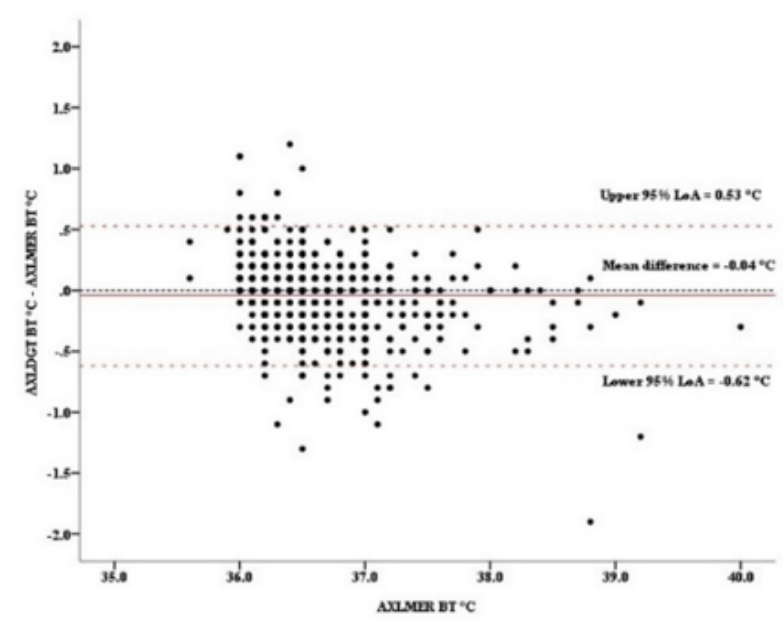

a) $\mathrm{AXL}_{\mathrm{DGT}}$ vs. Gold Standard

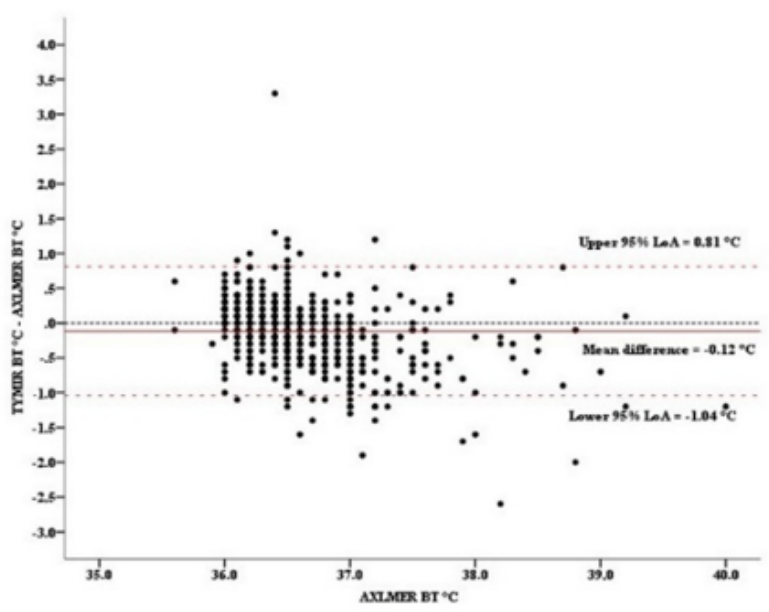

c) $\mathrm{TYM}_{\mathrm{IR}}$ vs. Gold Standard

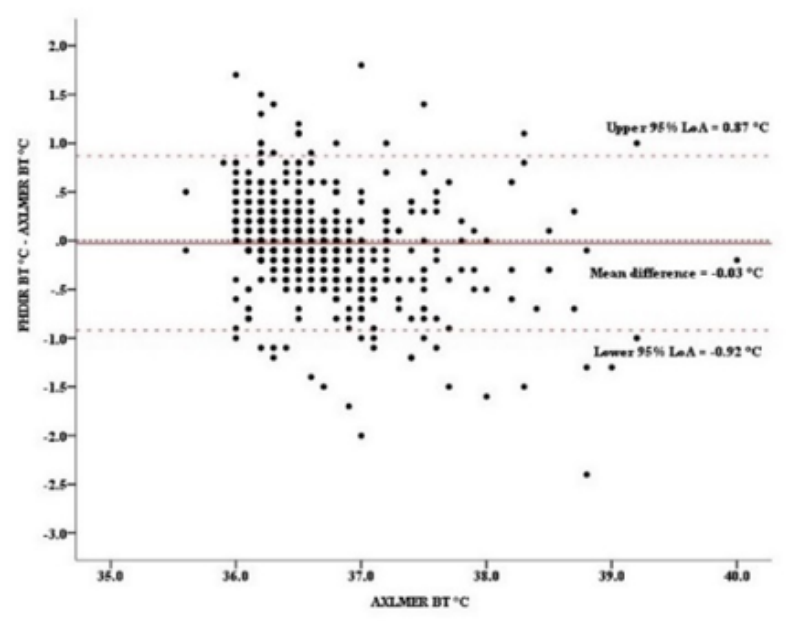

b) $\mathrm{FHD}_{\mathrm{IR}}$ vs. Gold Standard

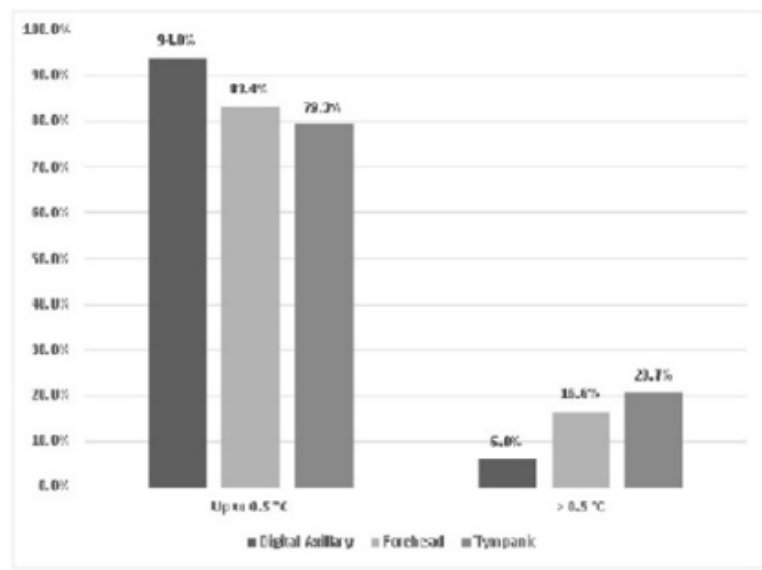

d) Percentage of mean differences between Mercury and other thermometers falling under $0.5^{\circ} \mathrm{C}$

Figure 3

Paired comparisons between the Gold Standard mercury thermometer and the other devices. Legend. a) AXLDGT vs. Gold Standard; b) FHDIR vs. Gold Standard; c) TYMIR vs Gold Standard; d) Percentage of mean differences between Mercury and other thermometers falling under $0.5^{\circ} \mathrm{C}$ 